\title{
Photo-Driven Si-C Bond Cleavage in Hexacoordinate Silicon Complexes
}

\begin{tabular}{|c|c|}
\hline Journal: & Zeitschrift für Anorganische und Allgemeine Chemie \\
\hline Manuscript ID: & zaac. 200900080 \\
\hline Wiley - Manuscript type: & Article \\
\hline $\begin{array}{r}\text { Date Submitted by the } \\
\text { Author: }\end{array}$ & 02-Feb-2009 \\
\hline Complete List of Authors: & $\begin{array}{l}\text { Wagler, Jörg; TU Bergakademie Freiberg, Inst. für Anorganische } \\
\text { Chemie } \\
\text { Roewer, Gerhard; TU Bergakademie Freiberg, Fak. Chemie und } \\
\text { Physik } \\
\text { Gerlach, Daniela; TU Bergakademie Freiberg, Inst. für Anorganische } \\
\text { Chemie }\end{array}$ \\
\hline Keywords: & Chelate, Hypercoordination, Rearangement, Schiff Base, Tin \\
\hline
\end{tabular}

\section{s) ScholarONE \\ Manuscript Central}




\section{Introduction}

One of the most intriguing aspects of silicon coordination chemistry is the activation of various $\mathrm{Si}-\mathrm{X}$ bonds upon "hypercoordination" of the Si-atom. In particular, one or two additional donor atoms brought into closer proximity of a silicon atom, hence giving rise to silicon penta- and hexacoordination, respectively, may provoke $\mathrm{Si}-\mathrm{X}$ bond splitting, i.e. a lowering of the silicon coordination number down to tetra- or pentacoordination, respectively. A great variety of reactions following this fundamental scheme can be found in the literature, e.g., the formation of tetracoordinate siliconium cations from $\mathrm{N}$-methylimidazole and trimethylsilylbromide [1] and $\mathrm{Si}-\mathrm{Cl}$ bond dissociation to yield pentacoordinate siliconium cations [2]. Furthermore, the release of initially Si-bound halides may provoke reactions at the ligand backbone [3]. As soon as $\mathrm{Si}-\mathrm{X}$ bonds other than Si-Halide are getting activated by Sihypercoordination, the groups $\mathrm{X}$ may exhibit reactivities of camouflaged nucleophiles, i.e., group X may attack electrophilic centres in the ligand backbone such as carbonyl and imine carbon atoms. Such reactivity was shown for hexacoordinate silacyclobutanes [4], allylsilanes [5], disilanes [6], cyanosilanes [7] and $\mathrm{H}$-silanes [8]. Even an unexpected alkyl group shift towards an imine ligand was reported recently [9]. Furthermore, coordination to silicon as central atom may induce rearrangements of isomeric

\footnotetext{
* Dr. J. Wagler, Prof. Dr. Gerhard Roewer Institut für Anorganische Chemie

TU Bergakademie Freiberg

Leipziger Str. 29

D-09596 Freiberg, Germany

Fax: (+49) 3731394058

E-mail: joerg.wagler@chemie.tu-freiberg.de, gerhard.roewer@chemie.tufreiberg.de
}

accompanied by olefin elimination. Irradiation of compounds (ONNO)SiRX, with $\mathrm{X}$ being a non-carbon sacrificial ligand, was shown to give rise to further side reactions: In case of $\mathrm{X}=\mathrm{F}$ the unexpected formation of $(\mathrm{ONNO}) \mathrm{SiF}_{2}$ was observed. In analogy to the photo-induced rearrangement of $(\mathrm{ONNO}) \mathrm{SiPh}_{2}$ the heavier congenor (ONNO) $\mathrm{GePh}_{2}$ exhibits similar reactivity, whereas the related tin compound $(\mathrm{ONNO}) \mathrm{SnPh}_{2}$ proved inert under these reaction conditions applied.

Keywords: Chelate; Hypercoordination; Rearrangement; Schiff Base; Tin

ligand moieties one into another [10] or even give rise to the Sitemplated formation of novel ligands [11].

Our recent research on hypercoordinate diorganosilanes [12] revealed remarkably activated $\mathrm{Si}-\mathrm{C}$ bonds, which, upon irradiation, are cleaved to yield a novel ligand moiety coordinated to the silicon atom (Scheme 1) [13]. Hexacoordination of the silicon atom was shown to be one of the keys to this reactivity pattern since pentacoordinate silicon compounds comprising related ligand backbones proved inert under similar reaction conditions [14]. Furthermore, the approach to the ligand within this 1,3-shift reaction proved to proceed towards the sterically less crowded imine carbon atom, as demonstrated with an asymmetric ONN'O' ligand [15]. In our herein presented study we elucidate further parameters which may control the direction of the reactions following photo-induced $\mathrm{Si}-\mathrm{C}$ bond cleavage.

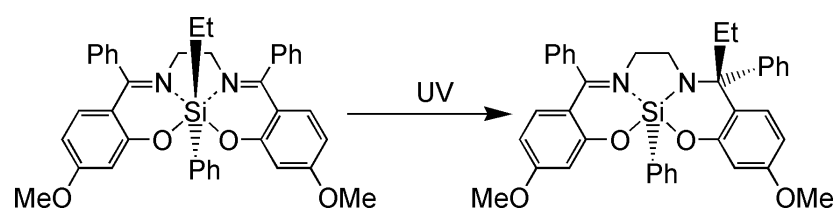

Scheme 1. 1,3-Shift of an initially Si-bound ethyl group upon UV irradiation.

\section{Results and Discussion}

As reported earlier, a variety of hexacoordinate diorganosilanes (28) was accessible via reaction between the tetradentate Schiff base ligand 1 and the respective diorganodichlorosilanes (Scheme 2) [12]. In accord with the exclusive 1,3-shift of the Si-bound alkyl group of $\mathbf{2}$ and $\mathbf{3}$ upon UV irradiation under formation of $\mathbf{2 a}$ and $\mathbf{3 a}$, respectively [13], in compound $\mathbf{4}$, which comprises a sterically more 
demanding alkyl substituent (i.e., a cyclohexyl group) the 1,3-alkyl shift is still favored.<smiles>COc1ccc(C(=NCCN=C(c2ccccc2)c2ccc(OC)cc2O)c2ccccc2)c(O)c1</smiles>

2: $\mathrm{R} / \mathrm{R}^{\prime}=\mathrm{Ph} / \mathrm{Me}$

3: $\mathrm{R} / \mathrm{R}^{\prime}=\mathrm{Ph} / \mathrm{Et}$

4: $\mathrm{R} / \mathrm{R}^{\prime}=\mathrm{Ph} / \mathrm{Cy}$

5: $\mathrm{R} / \mathrm{R}^{\prime}=\mathrm{Ph} / \mathrm{Ph}$

6: $\mathrm{R} / \mathrm{R}^{\prime}=\mathrm{Me} / \mathrm{Me}$

7: $\mathrm{R} / \mathrm{R} '=\mathrm{Vi} / \mathrm{Me}$

8: $\mathrm{R} / \mathrm{R}^{\prime}=\mathrm{Vi} / \mathrm{Ph}, \mathrm{Ph} / \mathrm{Vi}$

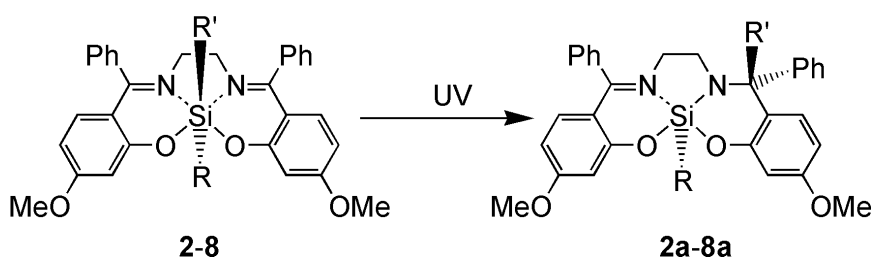

Scheme 2. Synthesis of hexacoordinate diorganosilanes 2-8 and their photo-assisted rearrangement into pentacoordinate silicon complexes $\mathbf{2 a - 8 a}$. For 2a-8a (not applicable for 5a) the diastereomer with swapped positions $\mathrm{R}^{\prime}$ vs. $\mathrm{Ph}$ was observed ${ }^{29} \mathrm{Si}$ NMR spectroscopically as a minor component $(<10 \%)$ of the reaction mixture. For $3 \mathbf{a}$ and $4 \mathbf{a}$ the product of $\beta$-hydride transfer $\left(\mathrm{R}^{\prime}=\mathrm{H}\right)$ was also observed NMR spectroscopically as a minor component $(<10 \%)$ [13].

Table 1. ${ }^{29} \mathrm{Si}$ NMR shifts $\left(\delta\right.$ in ppm relative to $\mathrm{SiMe}_{4}$ ) detected in the product mixture after irradiation of compounds 2-9, 11 and $\mathbf{1 3}$.

\begin{tabular}{llllll}
\hline & $\left.\delta^{29} \mathrm{Si}\right) 1^{[\mathrm{a}]}$ & $\left.\delta^{29} \mathrm{Si}\right) 2^{[\mathrm{b}]}$ & & $\left.\delta^{29} \mathrm{Si}\right) 1^{[\mathrm{a}]}$ & $\left.\delta^{29} \mathrm{Si}\right) 2^{[\mathrm{b}]}$ \\
\hline $\mathbf{2}$ & -113.3 & -115.8 & $\mathbf{7}$ & -115.5 & $-116.7,-101.5$ \\
$\mathbf{3}$ & -114.5 & $\mathbf{- 1 1 4 . 8 ^ { [ \mathrm { c } ] } , - 1 1 7 . 4}$ & $\mathbf{8}$ & -116.3 & $-113.3,-113.6,-114.6,-117.9$ \\
$\mathbf{4}$ & -112.7 & $\mathbf{- 1 1 4 . 8 ^ { [ \mathrm { c } ] }},-118.2$ & $\mathbf{9}$ & $\mathbf{- 1 1 4 . 8}$ & Other signals as for $\mathbf{8}$ \\
$\mathbf{5}$ & -113.9 & & $\mathbf{1 1}$ & -114.3 & -117.3 \\
$\mathbf{6}$ & -101.8 & -103.1 & $\mathbf{1 3}$ & $-129.5 \mathrm{~d}$ & \\
\hline
\end{tabular}

Table 2. ${ }^{13} \mathrm{C}$ NMR shifts ( $\delta$ in ppm relative to $\mathrm{SiMe}_{4}$ ) of the (Ph,Aryl,N,R)-substituted carbon atoms detected in the product mixture after irradiation of the hexacoordinate diorganosilicon compounds 2-9, 11 and $\mathbf{1 6}$.

\begin{tabular}{llllll}
\hline & $\delta\left({ }^{13} \mathrm{C}\right) 1^{[\mathrm{a}]}$ & $\delta\left({ }^{13} \mathrm{C}\right) 2^{[\mathrm{b}]}$ & & $\delta\left({ }^{13} \mathrm{C}\right) 1^{[\mathrm{a}]}$ & $\delta\left({ }^{13} \mathrm{C}\right) 2^{[\mathrm{b}]}$ \\
\hline $\mathbf{2}$ & $65.5^{[\mathrm{c}]}$ & & $\mathbf{7}$ & 65.5 & $64.3,70.5$ \\
$\mathbf{3}$ & $69.6^{[\mathrm{c}]}$ & & $\mathbf{8}$ & 70.2 & $68.2-73.1^{[\mathrm{e}]}$ \\
$\mathbf{4}$ & 72.6 & $\mathbf{6 9 . 2}^{[\mathrm{d}]}$ & $\mathbf{9}$ & $\mathbf{6 9 . 2}$ & Other signals as for $\mathbf{8}$ \\
$\mathbf{5}$ & 73.1 & & $\mathbf{1 1}$ & 70.1 & $\mathbf{6 9 . 2}$ \\
$\mathbf{6}$ & 65.4 & 64.1 & $\mathbf{1 6}$ & 74.2 &
\end{tabular}

${ }^{\text {a) Predominant signal }}{ }^{\text {b) }}$ Significant additional signal(s) in the spectra of the crude product $^{\text {c) }}$ The isolated major isomer ${ }^{\text {d) }}$ corresponds to the $\beta-\mathrm{H}$ transfer product ${ }^{\text {e) }} 9$ additional signals were observed from 68.2 to $73.1 \mathrm{ppm}$, thus indicating the formation of a great variety of products.

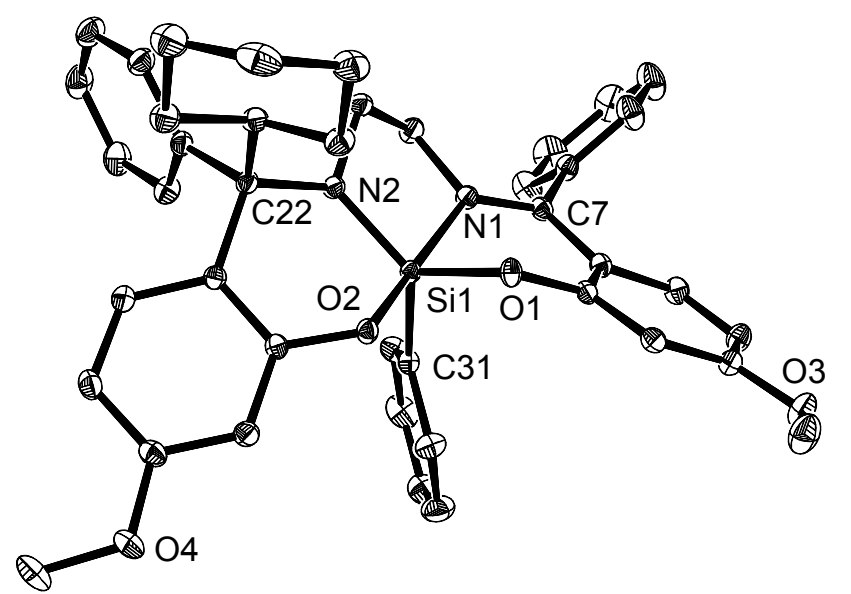

Figure 1. Molecular structure of $4 a$ in the crystal. (Thermal ellipsoids at the $20 \%$ probability level, H-atoms omitted, selected atoms labeled). Selected bond lengths $[\AA]$ and angles [deg.]: Sil-O1 1.706(1), Sil-O2 1.716(1), Si1-N1 1.989(1), Si1-N2 1.738(1), Si1-C31 1.886(2), N1-C7 1.295(2), N2-C22 1.496(2), O1-Si1-N2 126.3(1), O1-Si1-C31 108.9(1), N2-Si1-C31 123.5(1), O2-Si1-N1 171.5(1). For comparison the corresponding bond lengths and angles in molecule 5a in an isostructural crystal lattice: Si1-O1 1.711(1), Si1-O2 1.719(1), Si1-N1 1.987(1), Si1-N2 1.740(1), Si1-C31 1.889(2), N1-C7 1.295(2), N2-C22 1.495(2), O1-Si1-N2 126.1(1), O1-Si1-C31 109.6(1), N2-Si1-C31 123.0(1), O2-Si1-N1 171.7(1).

Even $\beta$-hydride transfer to the imine carbon atom, which was found as a minor side reaction when $\mathbf{3}$ was irradiated, did not play any pronounced role. Table 1 reveals the formation of pentacoordinate silicon complexes upon UV irradiation of 2, 3, 4 and 5. The very narrow ${ }^{29} \mathrm{Si}$ NMR shift range underlines the formation of silicon compounds bearing very similar Si-bound moieties, i.e., compounds comprising the (ONN'O')Si-Ph pattern. On the formation of a minor diasteromeric product in case of $\mathbf{2}$ and $\mathbf{3}$ as well as the $\beta$-hydride transfer product in case of $\mathbf{3}\left(\delta^{29} \mathrm{Si}\right.$ $=-114.8 \mathrm{ppm}$ ) we have reported earlier [13]. These features can also be found for compound $\mathbf{4}$, whereas the rearrangement product of 5 reveals only one ${ }^{29} \mathrm{Si}$ NMR signal, as expected. From the crude reaction products ${ }^{13} \mathrm{C}$ NMR spectra were recorded in order to gather information to the ${ }^{13} \mathrm{C}$ chemical shift of the altered former imine carbon atom (Table 2). In addition to the distinct signals of the characteristic R'PhArylN-substituted quarternary C-atoms, a resonance peak emerges at $69.2 \mathrm{ppm}$ for the $\beta-\mathrm{H}$ transfer product in case of the product mixtures resulting from $4,(9$ and 11 , vide infra, not recorded for $\mathbf{3}$ ).

We succeeded in crystallizing $4 \mathbf{a}$ from the reaction mixture (Fig. 1). As in 3a [13], the silicon atom in $\mathbf{4 a}$ is housed in a distorted trigonal bipyramidal coordination sphere. The bonding parameters about the Si-atom are similar to those found for 3a. The ultimate reactivity of the $\mathrm{Si}-\mathrm{C}($ alkyl) bond in $\mathbf{2}, \mathbf{3}$ and $\mathbf{4}$ gave rise to the question whether $\mathrm{Si}-\mathrm{C}($ aryl) might prove capable of rearranging in a similar manner. Hence, compound $\mathbf{5}$ was also irradiated, with success. The exclusive presence of $\mathrm{Si}-\mathrm{C}($ aryl $)$ bonds rendered an $\mathrm{Si}$ bound phenyl group suitable to rearrange. The molecular structure of the rearrangement product 5a (determined crystallographically) is similar to $\mathbf{4 a}$, thus not further discussed. Selected bonding parameters of $\mathbf{5 a}$ are provided in caption of Figure 1.

The next essential question addressed was the role of the phenyl group in the rearrangement reactions of 2-5. One could consider the phenyl moiety as an antenna for electromagnetic power input into the molecules, thus activating the $\mathrm{Si}-\mathrm{C}$ bond trans-disposed to $\mathrm{Si}-\mathrm{C}$ (phenyl). Successful rearrangement of one of the Si-bound methyl groups in $\mathbf{6}$ proved this hypothesis wrong and, furthermore, provided insights into the stability of the reaction product $\mathbf{6 a}$. So far, 
we only knew that the $\mathrm{Si}-\mathrm{C}(\operatorname{aryl})$ bonds in compounds such as $\mathbf{2 a -}$ 5a are not susceptible to any further UV-assisted rearrangement. In conclusion, this applies to $\mathrm{Si}-\mathrm{Me}$ as well. The formation of the proposed rearrangement product $\mathbf{6 a}$ and a diastereomer thereof is indicated in the ${ }^{29} \mathrm{Si}$ NMR spectrum by significantly down-field shifted signals (i.e., -101.8 and $-103.1 \mathrm{ppm}$ ) with respect to the $\mathrm{Si}-\mathrm{Ph}$ substituted pentacoordinate Si-complexes.

Vinyl substituted complexes 7 and $\mathbf{8}$ (Scheme 2, Table 1) deliver further information. The Si-bound vinyl group in compound 7 adopts the role of the phenyl group in 2, thus rendering the Si-bound methyl group most susceptible to photo-assisted 1,3-rearrangement to yield 7a. A minor product comprising a pentacoordinate Si-atom with an Si-bound methyl group (as indicated by a signal at -101.5 $\mathrm{ppm}$ ) proves the vinyl group less resistant towards rearrangement than the phenyl group. In addition, a ${ }^{13} \mathrm{C}$ NMR signal of a quarternary carbon atom at $70.5 \mathrm{ppm}$ (Table 2), which is in closer proximity to the signals of the $\mathrm{Ph}_{2}$ ArylN-substituted quarternary Catoms (see $73.1 \mathrm{ppm}$ for 5a), underlines the 1,3-shift of this $\mathrm{sp}^{2}$ carbon substituent in a competing reaction. Upon irradiation of compound 8, however, a product mixture results which can be explained by alternative rearrangement of vinyl and phenyl group. This is, the two $\mathrm{sp}^{2}$-carbon substituents $\mathrm{Ph}$ and $\mathrm{Vi}$ compete with each other. Hence, the $\mathrm{sp}^{3} v s \mathrm{sp}^{2}$ hybrid character of the Si-bound Csubstituent proved to dominate the course of the reaction. Therefore, we considered the molecular orbital situation along the $\mathrm{C}-\mathrm{Si}-\mathrm{C} 3-$ centre bond axis as a fundamental factor which determines the way an $\mathrm{Si}-\mathrm{C}$ bond in complexes such as $\mathbf{2 - 8}$ is cleaved.

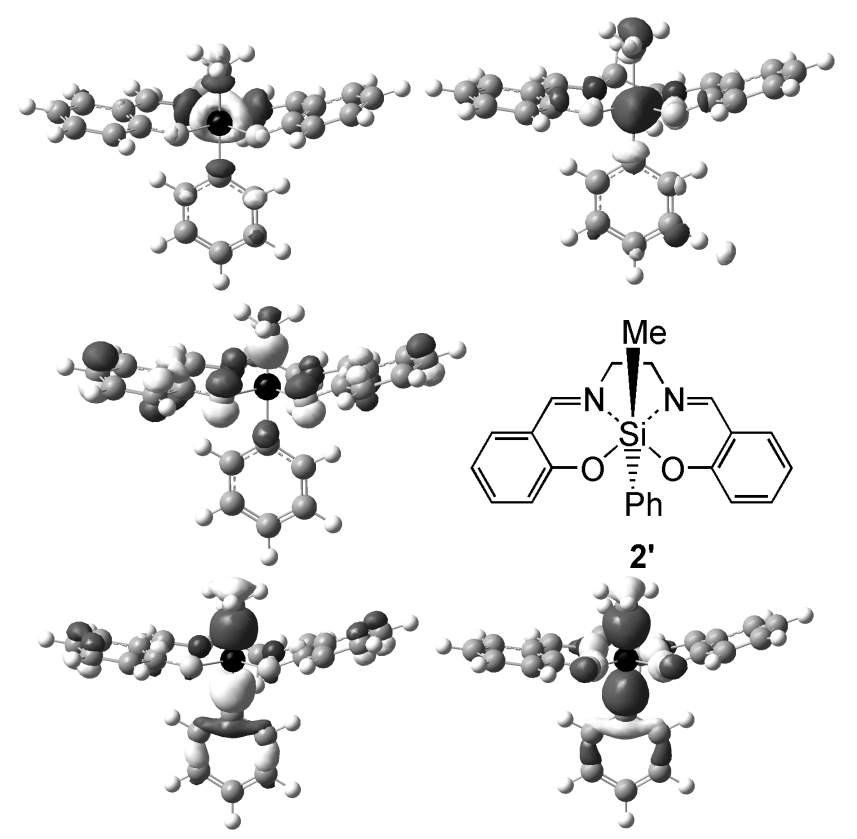

Figure 2. Molecular orbitals of 2' (from left) \#94, \#98 (bottom), \#102 = HOMO (middle), \#130, \#131 (top), which exhibit significant contributions on the $\mathrm{C}-\mathrm{Si}-\mathrm{C}$ bond axis (limiting isosurface: $0.05 \mathrm{e}^{-3}$ ). MO \#102 represents the HOMO.

A computational study of model compound 2' (Figure 2) revealed an interesting feature of the orbital situation along the $\mathrm{C}-\mathrm{Si}-\mathrm{C}$ axis (Figure 2). We were able to identify four orbitals (two bonding, i.e., \#94, \#98, and two anti-bonding ones, i.e., \#130, \#131) which exhibit noticeable contributions of a $\mathrm{C}-\mathrm{Si}-\mathrm{C}$ 3-centre bonding situation. Whereas the contributions of the $\mathrm{Si}-\mathrm{C}$ bonds to these orbitals are nearly equal, the HOMO (\#102) exhibits remarkable contributions from the $\mathrm{Si}-\mathrm{C}$ (methyl) bond to an $\mathrm{MO}$ which is predominantly created by $\pi$-interactions within the ligand system. One can assume that UV excitation of the HOMO would thus result in pronounced weakening of the $\mathrm{Si}-\mathrm{C}(\mathrm{Me})$ bond, whereas the $\mathrm{Si}-\mathrm{C}(\mathrm{Ph})$ bond would probably be less influenced. This is merely a little hint to the origin of the different 1,3 -shift behavior of the methyl and phenyl group. Further studies will have to address the investigation of the role of the tetradentate ligand as an antenna for the energy input.

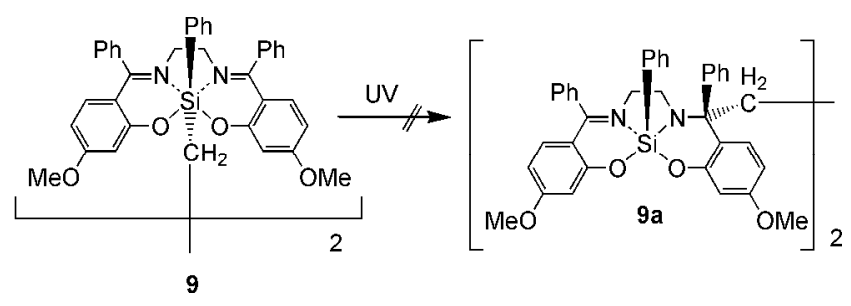

Scheme 3.

In a previous publication we have reported on the synthesis of a di-nuclear diorganosilane 9 comprising two hexacoordinate silicon atoms (Scheme 3) [16]. This tempted us to explore photo-induced rearrangement of this di-nuclear phenyl-alkyl-silane. In sharp contrast to our expectations, there was no indication for the formation of a dinuclear complex such as 9a. Instead, ${ }^{29} \mathrm{Si} \mathrm{NMR}$ spectroscopy of the product mixture thus obtained exhibited the same signal pattern as the ${ }^{29} \mathrm{Si}$ NMR spectrum of the products obtained upon irradiation of vinyl-phenyl-silane 8. Additionally, an intense peak at $-114.8 \mathrm{ppm}$ indicated the simultaneous formation of the equivalent amount of complex $9 \mathbf{b}$, which was previously found to be a side product in the rearrangement reaction of $\mathbf{3}$ and $\mathbf{4}$, i.e. resulting from $\beta$-hydride transfer. This conclusion was supported ${ }^{1} \mathrm{H}$ and ${ }^{13} \mathrm{C}$ NMR spectroscopically [17].

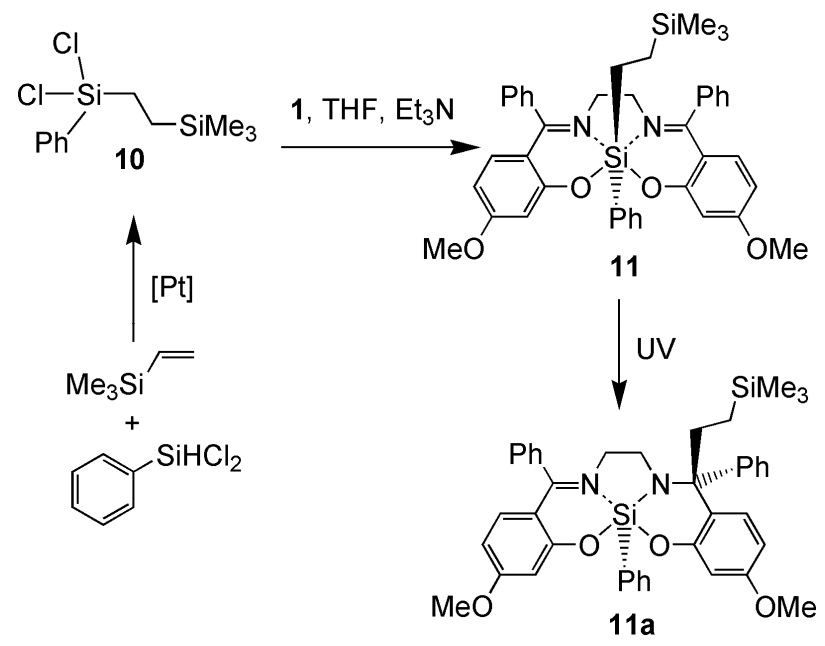

Scheme 4.

At least two parameters can be considered to drive the rearrangement reaction of 9 into this unexpected direction: 1) The $\beta$ silyl substituted alkyl group might exhibit an activating influence on the $\beta$-hydrogen atoms; 2) The steric bulk about the ethylene bridge might render the formation of two mono-nuclear complexes more likely. In order to rule out the first option, complex 11 was synthesized according to Scheme 4. Except the $\beta$-silyl substituent 
the structural features of the molecules of $\mathbf{1 1}$ (Figure 3) are related to those found for 3 [13]. Indeed, photo-induced rearrangement of 11 predominantly led to the undisturbed rearrangement of the 2trimethylsilylethyl group to yield 11a whereas $\beta$-hydride transfer was found to play the role of a minor side reaction as in the analogous reactions of $\mathbf{3}$ and $\mathbf{4}$.

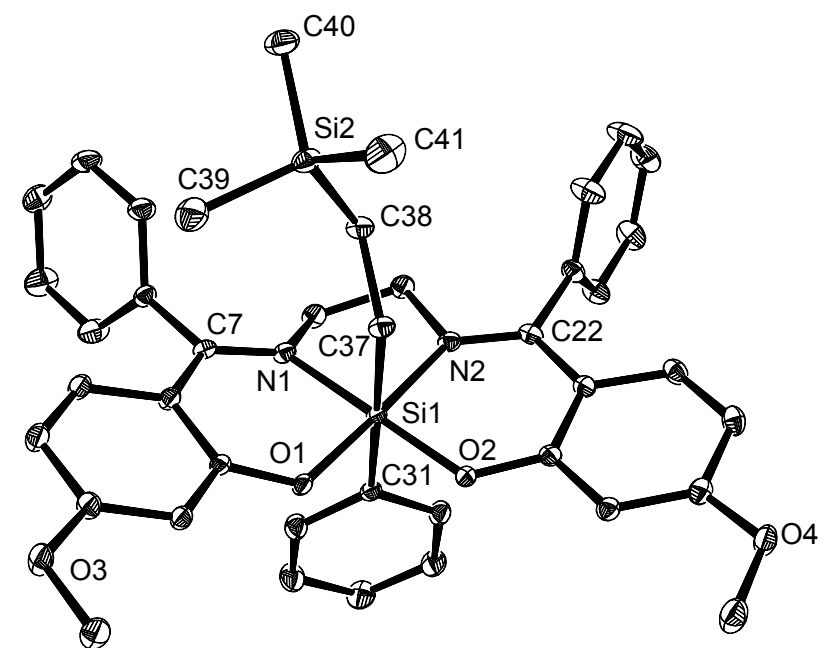

Figure 3. Molecular structure of one of the two crystallographically independent molecules of $\mathbf{1 1}$ in a crystal of $\mathbf{1 1}\left(\mathrm{CHCl}_{3}\right)_{2}$ (Thermal ellipsoids at the $50 \%$ probability level, $\mathrm{H}$-atoms and chloroform molecules omitted, selected atoms labeled). Selected bond lengths $[\AA]$ and angles [deg.]: Sil-O1 1.769(1), Si1-O2 1.770(1), Si1-N1 1.959(1), Si1-N2 1.960(1), Si1-C31 1.960(1), Si1-C37 1.970(1), N1-C7 1.299(2), N2-C22 1.298(2), N1-Si1-O2 175.5(1), N2-Si1-O1 176.8(1), C31-Si1-C37 176.4(1), Si1-C37-C38 122.6(1), Si2-C38-C37 115.1(1), Si1-C37-C38 122.6(1), Si2-C38-C37 115.1(1).

In all above rearrangement reactions a phenyl group (alternatively, a vinyl or methyl group) acts as a sacrificial ligand which does not undergo any 1,3-shift reaction. Whereas the $\mathrm{Si}-\mathrm{C}$ bond is only kinetically inert, an Si-F bond is thermodynamically more stable and might therefore prove a suitable sacrificial ligand as well. Thus, compound $\mathbf{1 3}$ was synthesized according to Scheme 5. Its identity (as the F-trans-phenyl isomer) was confirmed by ${ }^{1} \mathrm{H},{ }^{13} \mathrm{C}$ and ${ }^{29} \mathrm{Si}$ NMR spectroscopy. Whereas the ${ }^{1} \mathrm{H}$ and ${ }^{13} \mathrm{C}$ spectra exhibit only one set of NMR signals characteristic of half a tetradentate ligand, the ${ }^{29} \mathrm{Si}$ NMR spectrum $\left(\delta=-180.3 \mathrm{ppm}\right.$, dublett ${ }^{1} J_{\mathrm{SiF}}=166$ $\mathrm{Hz}$ ) reveals hexacoordination of the silicon atom and the presence of one fluorine atom in its coordination sphere. Upon UV-irradiation of 13 the expected rearrangement product 13a had formed (indicated by a dublet in the ${ }^{29} \mathrm{Si}$ NMR spectrum, $\delta=-129.5 \mathrm{ppm},{ }^{1} J_{\mathrm{SiF}}=188$ $\mathrm{Hz})$, but from the presence of an intense triplet signal $(\delta=-187.0$ $\left.\mathrm{ppm},{ }^{1} J_{\mathrm{SiF}}=174 \mathrm{~Hz}\right)$ the formation of an $\mathrm{SiF}_{2}$-substituted hexacoordinate silicon compound became instantly obvious. Deliberate synthesis and characterization of complex 15 (Scheme 5, bottom) proved identity with the side product formed upon UVirradiation of 13. So far, the fate of the originally Si-bound phenyl group is not clear. At least, due to the absence of a ${ }^{29} \mathrm{Si} \mathrm{NMR} \mathrm{signal}$ at $-113.9 \mathrm{ppm}$, we can exclude formation of $\mathbf{5 a}$ in a combined photolysis + ligand-scrambling reaction, in addition to having shown that an Si-bound phenyl group would be the dummy ligand of choice for such photo-driven rearrangement reactions.

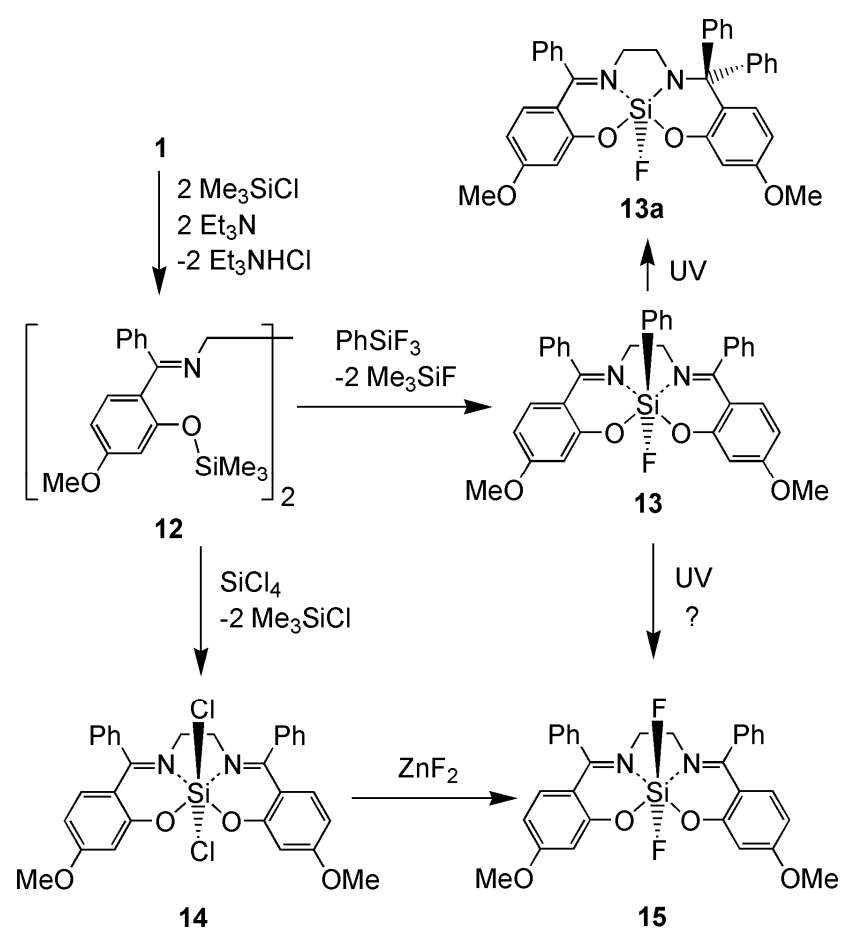

Scheme 5.
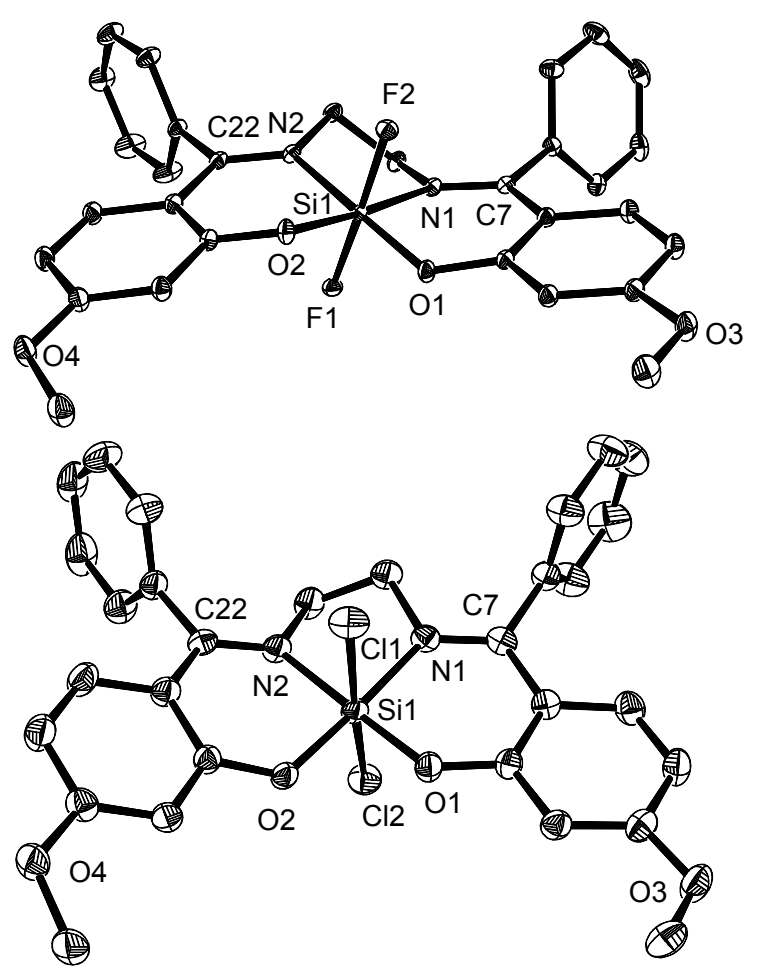

Figure 4. Molecular structures of $\mathbf{1 5}$ in a crystal of $\mathbf{1 5} .\left(\mathrm{CHCl}_{3}\right)_{2}$ (top) and $\mathbf{1 4}$ in a crystal of 14.(toluene) (bottom). (Thermal ellipsoids at the $50 \%$ probability level, $\mathrm{H}$-atoms and solvent molecules omitted, selected atoms labeled). Selected bond lengths $[\AA]$ and angles [deg.]: 15: Si1-O1 1.736(1), Si1-O2 1.728(1), Si1-N1 1.916(1), Si1-N2 1.926(1), Si1-F1 1.658(1), Sil-F2 1.678(1), N1-C7 1.300(1), N2-C22 1.297(1), O1-Si1-N2 176.8(1), O2-Si1-N1 175.9(1), F1-Si1-F2 174.2(1). 14: Si1-O1 1.705(1), Si1-O2 1.709(1), Si1-N1 1.901(1), Si1-N2 1.900(1), Si1-Cl1 2.267(1), Si1-Cl2 2.226(1), N1-C7 1.303(2), N2-C22 1.307(2), O1-Si1-N2 1.783(1), O2-Si1-N1 1.770(1), C11-Si1-Cl2 174.1(1).

Compounds 12, 14 and 15 were obtained as crystalline solids, thus allowing for X-ray diffraction analyses thereof. Compound $\mathbf{1 2}$ 
does not exhibit any unusual structural features. In sharp contrast to molecular structures of $\mathrm{SiMe}_{3}$ substituted salen-type ligands proposed by Singh et al. [18], 12 comprises $\mathrm{SiMe}_{3}$ groups with tetracoordinate silicon atoms. Both compounds 14 and 15 represent hexacoordinate silicon complexes with significantly longer $\mathrm{Si}-\mathrm{N}$ and $\mathrm{Si}-\mathrm{O}$ bonds in the fluorosilicon compound $\mathbf{1 5}$. In previous studies we have also recognized this coordinative behavior of bond lengthening upon $\mathrm{Cl} v s$. F substitution [19]. It can be interpreted as enhanced $\mathrm{O}$ and $\mathrm{N}$ donor action in chlorosilicon complexes owing to the longer $\mathrm{Si}-\mathrm{Cl}$ bond with pronounced ionic contributions [20].

In addition to Si-substituent effects, the influence of the group 14 element on this kind of rearrangement was to be considered. Therefore, two Ge- and Sn-compounds (16 and 17, respectively) were synthesized starting from ligand $\mathbf{1}$, triethylamine and the desired diphenyldichlorometallane $\mathrm{Ph}_{2} \mathrm{ECl}_{2} \quad(\mathrm{E}=\mathrm{Ge}$, Sn, respectively). The molecular structures of these compounds were determined X-ray crystallographically. The molecular shape of the germanium complex 16 (Figure 5) is related to its silicon analogue 5 [12]. This is a hexacoordinate Ge-complex comprising transdisposed $\mathrm{Ge}-\mathrm{C}$ bonds.

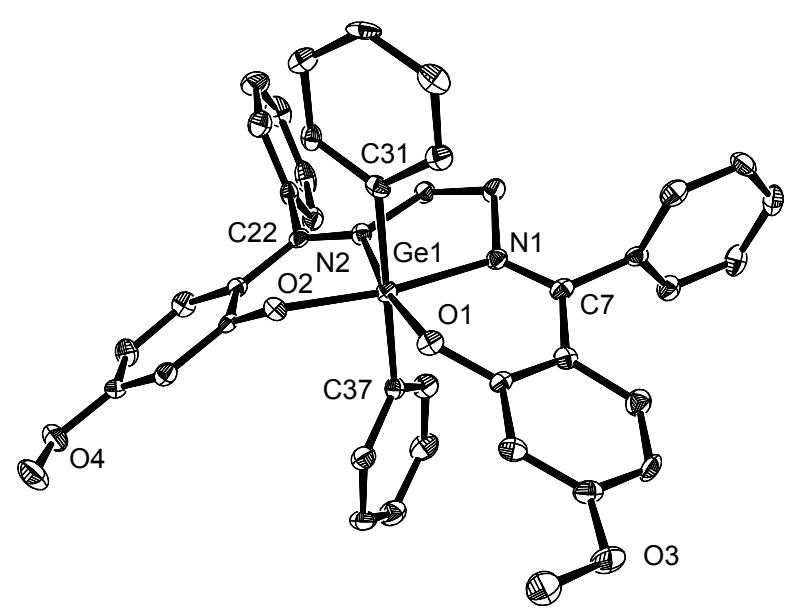

Figure 5. Molecular structure of $\mathbf{1 6}$ in the crystal. (Thermal ellipsoids at the $50 \%$ probability level, H-atoms omitted, selected atoms labeled). Selected bond lengths $[\AA]$ and angles [deg.]: Ge1-O1 1.928(2), Ge1-O2 1.936(2), Ge1-N1 2.057(2), Ge1-N2 2.086(2), Ge1-C31 2.005(3), Ge1-C37 1.995(3), N1-C7 1.289(3), N2-C22 1.285(3), O1-Ge1-N2 170.6(1), O2-Ge1-N1 170.2(1), C31-Ge1-C37 177.0(1).

The molecular structure of Sn-complex 17 (Figure 6) was entirely different. Surprisingly, compound $\mathbf{1 7}$ exhibits the tetradentate (ONNO) ligand in a mer-fac coordination mode. In a previous report [21] we had demonstrated that a complex of the type (ONNO)SnPhCl with a related salen-type ligand might exhibit this unexpected coordination pattern whereas in other salen-Sncomplexes (ONNO)SnR 2 (comprising two identical substituents $\mathrm{R}$ ) the Sn-bound monodentate groups $\mathrm{R}$ are trans-disposed to one another [22]. Now complex 17 clearly shows that even complexes of the general pattern (ONNO) $\mathrm{SnR}_{2}$ may also comprise a salen-type ligand in mer-fac coordination mode. (In solution, however, the tetradentate ligand backbone of compound $\mathbf{1 7}$ may also engage the mer-mer coordination mode, as concluded from ${ }^{13} \mathrm{C}$ and ${ }^{1} \mathrm{H}$ NMR spectroscopic data, which render the two $\mathrm{CH}_{2}$ and $\mathrm{CH}_{3}$ groups and the methylene protons of each $\mathrm{CH}_{2}$ group chemically equivalent.) In addition to the structural differences between $\mathbf{1 6}$ and $\mathbf{1 7}$ in the solid state, their reactivity upon UV-irradiation proved different. Whereas complex 16 gives rise to UV-induced $\mathrm{Ge}-\mathrm{C}$ bond cleavage and migration of a phenyl group to the ligand backbone (as described for above hexacoordinate silicon complexes such as $\mathbf{5}$ ), unaltered compound $\mathbf{1 7}$ was recovered from the UV reactor, and there was no indication for the formation of another tin compound other than $\mathbf{1 7 .}$ The identity of the rearrangement product resulting from compound 16 was established by comparison of its ${ }^{13} \mathrm{C}$ NMR data with the corresponding data of the related silicon compound 5a. This is: In addition to the emerging of a signal indicative of a $\mathrm{Ph}_{2} \mathrm{ArylN}$ substituted quarternary C-atom at $74.2 \mathrm{ppm}$ (Table 2) two sets of two signals arise for the two chemically inequivalent OMe groups and the $\mathrm{N}_{-} \mathrm{CH}_{2} \mathrm{CH}_{2}-\mathrm{N}$ unit of the ligand backbone (55.7, 55.0 and 49.9, $46.3 \mathrm{ppm}$ for 5a; 55.6, 55.0 and 49.1, $46.2 \mathrm{ppm}$ for its analogue 16a).

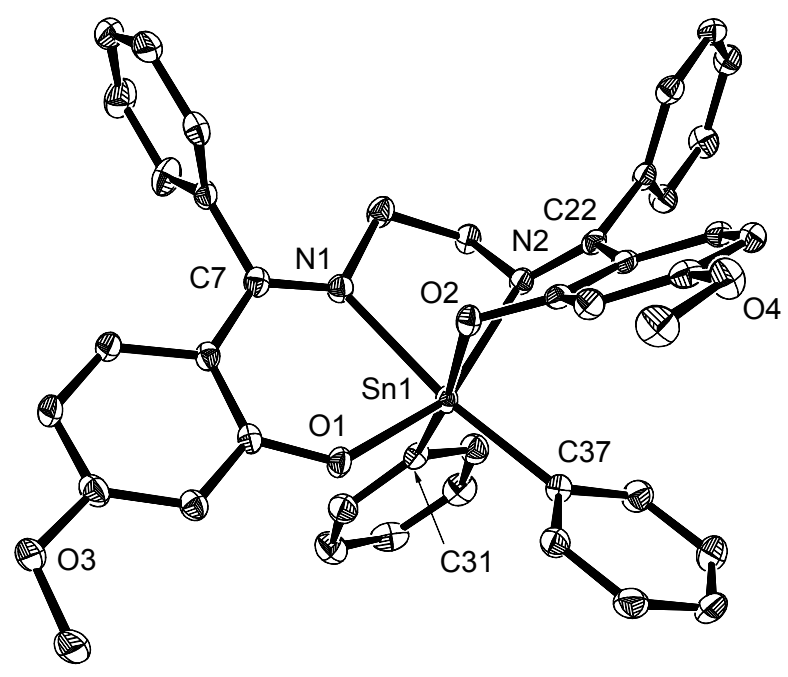

Figure 6. Molecular structure of $\mathbf{1 7}$ in the crystal. (Thermal ellipsoids at the $50 \%$ probability level, H-atoms omitted, selected atoms labeled). Selected bond lengths $[\AA]$ and angles [deg.]: Sn1-O1 2.049(2), Sn1-O2 2.127(2), Sn1-N1 2.303(2), Sn1-N2 2.205(2), Sn1-C31 2.177(3), Sn1-C37 2.156(3), N1-C7 1.296(3), N2-C22 1.321(3), O1-Sn1-N2 152.6(1), O2-Sn1-C31 171.5(1), N1-Sn1-C37 169.0(1), C31-Sn1-C37 100.7(1).

In order to elucidate the differences between $\mathbf{1 6}$ and $\mathbf{1 7}$ in both reactivity and structural patterns, computational analyses were performed at the MP2/SDD level of theory, in which the gas phase geometries of the hexacoordinate group 14 compounds SI, GE and SN as well as SN' (the cis-C-Sn-C isomer) and their potential rearrangement products SIa, GEa and SNa were optimized. Their relative energies (Scheme 6) hint to the general trend of decreasing thermodynamic driving force (by means of enthalpy) for the M-C bond cleavage and phenyl shift reaction, although above data still renders the rearrangement of $\mathbf{S N}$ into $\mathbf{S N a}$ a slightly exothermic reaction. Furthermore, the difference in energy between $\mathbf{S N}$ and $\mathbf{S N}$ ' $(4.8 \mathrm{kcal} / \mathrm{mol})$ proves the structure of $\mathbf{1 7}$ an unexpected case, less favorable than its trans-C-Sn-C isomer. This finding is well in accord with a computational study by Tacke et al., which proved a mer-mer coordinated silicon complex within a tetradentate ONNO ligand system more stable than its mer-fac isomer [23]. The rather small difference in energy, however, shows that the special ligand arrangement in $\mathbf{1 7}$ in the solid state may arise for reasons such as crystal packing effects and revert into the more favorable arrangement upon dissolution (as found in NMR spectra). 


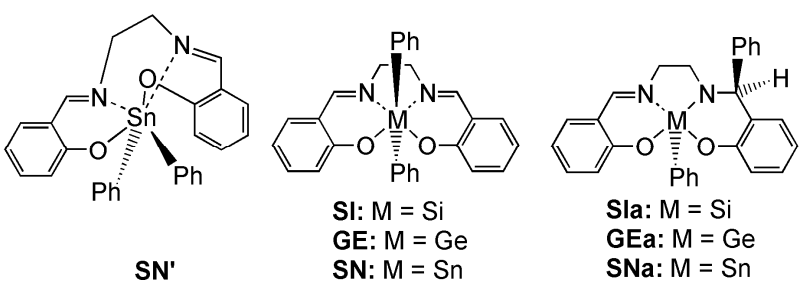

Scheme 6. Relative energies ( $\mathrm{kcal} / \mathrm{mol})$ with respect to $\mathbf{S I}, \mathbf{G E}$ and $\mathbf{S N}$, respectively, which were set 0: SIa $-21.0 ; \mathbf{G E a}-13.9 ; \mathbf{S N}^{\prime}+4.8, \mathbf{S N a}-8.3$.

In Conclusion, the Si-bound phenyl group of hexacoordinate diorganosilanes was shown to be a suitable sacrificial ligand in UVinduced 1,3-shift reactions of one Si-bound organyl group to an imine carbon atom of an imine ligand. Whereas an Si-bound vinyl group proved to compete with alkyl groups, the Si-bound phenyl substituent behaves innocent. The selective 1,3-shift of an $\mathrm{sp}^{2}-\mathrm{C}-$ substituent was successful for the $\mathrm{SiPh}_{2}$-substitution pattern only, whereas competing rearrangements were encountered for a (ONNO)SiPhVi system. Although thermodynamically tight bound to the silicon atom, a fluorine substituent cannot adopt the role of a sacrificial ligand for such cases to overcome competing reactions: The Si-F group leads to further side reactions (rearrangement reactions), the mechanisms of which are not clear yet. Furthermore, $\beta-\mathrm{H}$ bearing alkyl substituents were shown to contribute to the range of side reactions by $\beta-\mathrm{H}$ transfer to the imine group to variable extent. As to the role of the group 14 element, a related $(\mathrm{ONNO}) \mathrm{GePh}_{2}$ system was shown to undergo a similar UV-induced 1,3-rearrangement of a Ge-bound phenyl group whereas a $(\mathrm{ONNO}) \mathrm{SnPh}_{2}$ system proved inert under the reaction conditions applied.

\section{Experimental Section}

\section{Syntheses, NMR spectroscopy and X-ray crystallography}

Syntheses were performed under an inert atmosphere of dry argon using Schlenk line techniques and anhydrous solvents. NMR spectra (of $\mathrm{CDCl}_{3}$ solutions) were recorded on a BRUKER DPX 400 spectrometer $(10 \mathrm{~mm}$ probe) using $\mathrm{SiMe}_{4}$ as internal standard for ${ }^{1} \mathrm{H},{ }^{13} \mathrm{C}$ and ${ }^{29} \mathrm{Si}$ spectra. X-ray diffraction data were recorded on a BRUKER NONIUS X8 diffractometer with APEX II CCD detector using Mo K $\alpha$ radiation. The structures were solved by direct methods (SHELXS) and refined with full-matrix leastsquares on $F^{2}$. All non-hydrogen atoms were refined anisotropically. Hatoms were refined isotropically in idealized positions (riding model). Crystallographic data for the structures have been deposited with the Cambridge Crystallographic Data Centre, CCDC-718481 (4a), CCDC718483 (5a), CCDC-718486 (11.( $\left.\left.\mathbf{C H C l}_{3}\right)_{2}\right)$, CCDC-718480 (12), CCDC718479 (14.toluene), CCDC-718484 (15. $\left.\left(\mathbf{C H C l}_{3}\right)_{2}\right), \quad$ CCDC-718487 $\left(\mathbf{1 5 . 0}-\mathbf{C}_{6} \mathbf{H}_{4}(\mathbf{O H})_{2}\right)$, CCDC-718482 (16) and CCDC-718485 (17). Copies of the data can be obtained free of charge online via www.ccdc.cam.ac.uk/data_request/cif.

The syntheses of compounds $\mathbf{2}-\mathbf{8}[12,13]$ and $\mathbf{9}[16]$ were reported earlier. Irradiation of the compounds $\mathbf{2}-\mathbf{9 , 1 1}$ and $\mathbf{1 3}$ with UV followed the protocol as reported for $\mathbf{2}$ and $\mathbf{3}$ in our preliminary communication [13]. This is, a 150 $\mathrm{mL}$ reactor equipped with a magnetic stirring bar and a medium pressure $\mathrm{Hg}$ lamp $\left(\lambda_{\max }=365-436 \mathrm{~nm}\right)$ was charged with $130 \mathrm{~mL}$ of tetrahydrofuran (THF) and ca. $5 \mathrm{mmol}$ of the respective hexacoordinate silicon complex. The solution or suspension was then exposed to UV for ca. $5 \mathrm{~h}$ (at $15^{\circ} \mathrm{C}$ ), whereupon the resulting solution was transferred into a Schlenk flask, the solvent was removed under reduced pressure and the residue was dissolved in $\mathrm{CDCl}_{3}$ for NMR analyses. As to further purification of the rearrangement products, our attempts to recrystallize the crude products under anaerobic conditions failed (except compounds $\mathbf{2 a}$ and $\mathbf{3 a}$, which were characterized as pure solids). As shown previously [13] compounds such as 2a and 3a undergo solvolysis in chloroform/methanol mixture. However, in case of the rearrangement products $4 \mathbf{a}$ and $5 \mathbf{a}$ some single crystals suitable for X-ray diffraction analyses were obtained by immediate addition of anhydrous methanol $(2 \mathrm{~mL})$ to a solution of the respective crude product in chloroform $(1 \mathrm{~mL})$. Although this is not the method of choice, the $\mathrm{Cy}-$ and $\mathrm{Ph}-$ substituted ligands presumably do both suppress solvolysis noticeably and allow for rapid crystallization. The solid state structures of $\mathbf{4 a}$ and $\mathbf{5 a}$ confirm cyclohexyl- and phenyl-1,3-migration to the tetradentate ligand, respectively. Crystal structure analysis of $4 \mathrm{a}: \mathrm{C}_{42} \mathrm{H}_{42} \mathrm{~N}_{2} \mathrm{O}_{4} \mathrm{Si}, M_{\mathrm{r}}=666.87, T=$ $296(2) \mathrm{K}$, monoclinic, space group $P 2_{1} / n, a=14.5474(5), b=15.0231(5), c$ $=17.2716(6) \AA, \beta=113.388(2)^{\circ}, V=3464.5(2) \AA^{3}, Z=4, \rho_{\text {calcd }}=1.279$ $\mathrm{Mgm}^{-3}, \mu(\mathrm{Mo} \mathrm{K} \alpha)=0.114 \mathrm{~mm}^{-1}, F(000)=1416,2 \theta_{\max }=54.0^{\circ}, 27597$ collected reflections, 7547 unique reflections $\left(R_{\text {int }}=0.0385\right), 444$ parameters, $S=1.052, R_{1}=0.0431(I>2 \sigma(I)), w R_{2}$ (all data) $=0.1107, \mathrm{max} . / \mathrm{min}$. residual electron density $+0.256 /-0.342 \mathrm{e}^{-3}$. Crystal structure analysis of $5 \mathbf{a}$ : $\mathrm{C}_{42} \mathrm{H}_{36} \mathrm{~N}_{2} \mathrm{O}_{4} \mathrm{Si}, M_{\mathrm{r}}=660.82, T=296(2) \mathrm{K}$, monoclinic, space group $P 2{ }_{1} / n, a=$ $14.3526(6), b=15.0411(5), c=17.1985(7) \AA, \beta=112.836(1)^{\circ}, V=$ $3421.8(2) \AA^{3}, Z=4, \rho_{\text {calcd }}=1.283 \mathrm{Mgm}^{-3}, \mu\left(\mathrm{Mo} \mathrm{K}_{\alpha}\right)=0.115 \mathrm{~mm}^{-1}, F(000)=$ $1392,2 \theta_{\max }=56.0^{\circ}, 33530$ collected reflections, 8244 unique reflections $\left(R_{\text {int }}=0.0347\right), 442$ parameters, $S=1.052, R_{1}=0.0434 \quad(I>2 \sigma(I)), \quad w R_{2}$ (all data $=0.1168, \mathrm{max} . / \mathrm{min}$. residual electron density $+0.263 /-0.320 \mathrm{e}^{-3}$.

Synthesis of compound 10: The hydrosilylation of vinyltrimethylsilane (4.0 $\mathrm{g}, 40 \mathrm{mmol})$ with phenyldichlorosilane $(6.60 \mathrm{~g}, 37.3 \mathrm{mmol})$ was carried out in chlorotrimethylsilane $(5 \mathrm{~mL})$ as a solvent using a Pt catalyst as described for the related synthesis of $\mathrm{PhCl}_{2} \mathrm{Si}-\mathrm{CH}_{2} \mathrm{CH}_{2}-\mathrm{SiCl}_{2} \mathrm{Ph}$ [16]. After removal of the solvent and excess vinyltrimethylsilane the Pt catalyst was allowed to precipitate and compound $\mathbf{1 0}$ was obtained as colorless liquid (quantitative yield) and used for the synthesis of 11 without further purification. ${ }^{1} \mathrm{H}$ NMR $\left(\delta / \mathrm{ppm}, \mathrm{CDCl}_{3}\right): 0.03\left(\mathrm{~s}, 9 \mathrm{H}, \mathrm{Si}-\mathrm{CH}_{3}\right), 0.6\left(\mathrm{~m}, 2 \mathrm{H}, \mathrm{Me}_{3} \mathrm{Si}-\mathrm{CH}_{2}\right), 1.2(\mathrm{~m}, 2 \mathrm{H}$ $\left.\mathrm{PhCl}_{2} \mathrm{Si}-\mathrm{CH}_{2}\right), 7.40-7.55(\mathrm{~m}, 3 \mathrm{H}), 7.65-7.75(\mathrm{~m}, 2 \mathrm{H}) .{ }^{13} \mathrm{C} \mathrm{NMR}(\delta / \mathrm{ppm}$, $\left.\mathrm{CDCl}_{3}\right)$ : -2.3 $\left(\mathrm{Si}-\mathrm{CH}_{3}\right), 7.6\left(\mathrm{Me}_{3} \mathrm{Si}-\mathrm{CH}_{2}\right), 13.7\left(\mathrm{PhCl}_{2} \mathrm{Si}-\mathrm{CH}_{2}\right), 128.3,133.5$ $(\mathrm{Ph} o / m), 131.5(\mathrm{Ph} p), 132.4(\mathrm{Ph} i) .{ }^{29} \mathrm{Si} \mathrm{NMR}\left(\delta / \mathrm{ppm}, \mathrm{CDCl}_{3}\right): 3.8\left(\mathrm{CH}_{2}\right.$ $\left.\mathrm{SiMe}_{3}\right), 19.8\left(\mathrm{CH}_{2}-\mathrm{SiPhCl}_{2}\right)$

Synthesis of compound 11: To a stirred suspension of ligand 1 (5.00 g, 10.4 $\mathrm{mmol})$ and triethylamine $(3.0 \mathrm{~g}, 30 \mathrm{mmol})$ in THF $(150 \mathrm{~mL})$ silane $\mathbf{1 0}(2.95$ $\mathrm{g}, 10.7 \mathrm{mmol})$ was added dropwise, whereupon $\left[\mathrm{Et}_{3} \mathrm{NH}\right]^{+} \mathrm{Cl}^{-}$precipitated. The resulting mixture was stirred at room temperature for $5 \mathrm{~min}$. Then the hydrochloride precipitate was filtered off and washed with THF $(20 \mathrm{~mL})$. From the combined filtrate and washings the solvent was removed in vacuo and the yellow residue was dissolved in chloroform $(35 \mathrm{~mL})$. This solution was then heated to reflux and hexane $(40 \mathrm{~mL})$ was slowly added. This clear yellow solution was stored at $8^{\circ} \mathrm{C}$ for 5 days to yield 11.(C $\left.\mathbf{C H C l}_{3}\right)_{2}$ as yellow crystals, which were filtered, washed with a mixture of chloroform $(2 \mathrm{~mL})$ and hexane $(4 \mathrm{~mL})$ and were briefly dried in vacuo. Yield $4.50 \mathrm{~g}(4.87 \mathrm{mmol}$, $47 \%$ ) of compound 11. $\left(\mathbf{C H C l}_{3}\right)_{2}$ as yellow solid. $\mathrm{C} / \mathrm{H} / \mathrm{N}$ analysis found (\%): C 56.02, H 4.91, N 3.19. Calcd. for $\mathrm{C}_{43} \mathrm{H}_{46} \mathrm{~N}_{2} \mathrm{O}_{4} \mathrm{Si}_{2} \mathrm{Cl}_{2}$ (923.70) (\%): C 55.89, $\mathrm{H} 5.02, \mathrm{~N} 3.03 .{ }^{1} \mathrm{H}$ NMR $\left(\delta / \mathrm{ppm}, \mathrm{CDCl}_{3}\right):-0.21\left(\mathrm{~s}, 9 \mathrm{H}, \mathrm{Si}-\mathrm{CH}_{3}\right), 0.6(\mathrm{~m}, 2 \mathrm{H}$ $\left.\mathrm{Me}_{3} \mathrm{Si}-\mathrm{CH}_{2}\right), 0.9$ (m, $\left.2 \mathrm{H}, \mathrm{Ph}(\mathrm{ONNO}) \mathrm{Si}-\mathrm{CH}_{2}\right), 3.14\left(\mathrm{~m}, 4 \mathrm{H}, \mathrm{N}-\mathrm{CH}_{2}\right), 3.78(\mathrm{~s}$, $\left.6 \mathrm{H}, \mathrm{O}-\mathrm{CH}_{3}\right), 6.07$ (dd, $\left.2 \mathrm{H}, 2.4 \mathrm{~Hz}, 8.8 \mathrm{~Hz}\right), 6.48$ (d, $\left.2 \mathrm{H}, 2.4 \mathrm{~Hz}\right), 6.52$ (d, 2 $\mathrm{H}, 8.8 \mathrm{~Hz}), 6.90-7.15(\mathrm{~mm}, 7 \mathrm{H}), 7.25-7.45(\mathrm{~m}, 6 \mathrm{H}), 7.65-7.70(\mathrm{~m}, 2 \mathrm{H})$. ${ }^{13} \mathrm{C}$ NMR $\left(\delta / p p m, \mathrm{CDCl}_{3}\right):-1.9\left(\mathrm{Si}-\mathrm{CH}_{3}\right), 14.8,23.5\left(\mathrm{Si}_{-} \mathrm{CH}_{2}-\mathrm{CH}_{2}-\mathrm{Si}\right), 48.3$ $\left(\mathrm{N}-\mathrm{CH}_{2}-\mathrm{CH}_{2}-\mathrm{N}\right), 55.3\left(\mathrm{OCH}_{3}\right), 104.3,106.1,114.7,124.7,126.1,126.3$, $126.4,128.9,129.1,129.2,133.1,134.5,135.6,163.9,165.7,166.0,170.1$. ${ }^{29} \mathrm{Si}$ NMR $\left(\delta / \mathrm{ppm}, \mathrm{CDCl}_{3}\right): 1.5,-169.3$. Crystal structure analysis of 11. $\left(\mathbf{C H C l}_{3}\right)_{2}: \mathrm{C}_{43} \mathrm{H}_{46} \mathrm{~N}_{2} \mathrm{O}_{4} \mathrm{Si}_{2} \mathrm{Cl}_{6}, M_{\mathrm{r}}=923.70, T=93(2) \mathrm{K}$, triclinic, space group $P-1, a=12.9235(4), b=13.2011(4), c=30.1001(9) \AA, \alpha=83.339(2)$, $\beta=80.573(2), \gamma=62.851(1)^{\circ}, V=4502.7(2) \AA^{3}, Z=4, \rho_{\text {calcd }}=1.363 \mathrm{Mgm}^{-3}$, $\mu\left(\mathrm{Mo} \mathrm{K}_{\alpha}\right)=0.478 \mathrm{~mm}^{-1}, F(000)=1920,2 \theta_{\max }=60.0^{\circ}, 102690$ collected reflections, 26200 unique reflections $\left(R_{\text {int }}=0.0343\right), 1085$ parameters, $S=1.146, R_{1}=0.0490(I>2 \sigma(I)), w R_{2}$ (all data) $=0.1630, \mathrm{max} . / \mathrm{min}$. residual electron density $+1.144 /-0.743 \mathrm{e}^{-3}$.

Synthesis of compound 12: In contrast to our previously reported method, [2a] this attempt allowed for the isolation of $\mathbf{1 2}$ as a crystalline solid: Ligand 1 (5.00 g, $10.4 \mathrm{mmol})$ and hexamethyldisilazane $(2.52 \mathrm{~g}, 15.7 \mathrm{mmol})$ were placed in a $100 \mathrm{~mL}$ Schlenk flask and were stirred at $125^{\circ} \mathrm{C}$ for $3 \mathrm{~h}$ to yield a clear yellowish solution (as expected the evolution of gas, $\mathrm{NH}_{3}$, was observed). Within 2 days at ambient temperature compound $\mathbf{1 2}$ crystallized from this mixture. The solid was then stirred with a mixture of hexane (5 $\mathrm{mL})$ and hexamethyldisilazane $(5 \mathrm{~mL})$, filtered off, washed with hexane $(10$ $\mathrm{mL})$ and dried in vacuo to yield $5.80 \mathrm{~g}(9.28 \mathrm{mmol}, 89 \%)$ of compound 12 as colorless solid. $\mathrm{Mp} 135^{\circ} \mathrm{C}, \mathrm{C} / \mathrm{H} / \mathrm{N}$ analysis found (\%): $\mathrm{C} 69.15, \mathrm{H} 7.03, \mathrm{~N}$ 4.67. Calcd. for $\mathrm{C}_{36} \mathrm{H}_{44} \mathrm{~N}_{2} \mathrm{O}_{4} \mathrm{Si}_{2}$ (624.91) (\%): C 69.19, H 7.10, N 4.48. ${ }^{1} \mathrm{H}$ $\operatorname{NMR}\left(\delta / \mathrm{ppm}, \mathrm{CDCl}_{3}\right): 0.04\left(\mathrm{~s}, 18 \mathrm{H}, \mathrm{Si}-\mathrm{CH}_{3}\right), 3.76\left(\mathrm{~m}, 4 \mathrm{H}, \mathrm{N}-\mathrm{CH}_{2}\right), 3.82(\mathrm{~s}$, $\left.6 \mathrm{H}, \mathrm{O}-\mathrm{CH}_{3}\right), 6.42$ (d, $\left.2 \mathrm{H}, 2.4 \mathrm{~Hz}\right), 6.5-6.6(\mathrm{~m}, 2 \mathrm{H}), 6.96(\mathrm{~d}, 2 \mathrm{H}, 8.4 \mathrm{~Hz})$, 7.2-7.35 (m, $6 \mathrm{H}), 7.56(\mathrm{~d}, 4 \mathrm{H}, 6.8 \mathrm{~Hz}) .{ }^{13} \mathrm{C} \mathrm{NMR}\left(\delta / \mathrm{ppm}, \mathrm{CDCl}_{3}\right): 0.3(\mathrm{Si}-$ $\left.\mathrm{CH}_{3}\right), 55.3\left(\mathrm{OCH}_{3}\right), 55.5\left(\mathrm{~N}-\mathrm{CH}_{2}\right), 105.7,106.1,121.0,127.8,128.0,129.3$, $130.3,130.4,140.7,153.6,160.3,160.7,166.1 .{ }^{29} \mathrm{Si} \mathrm{NMR}\left(\delta / \mathrm{ppm}, \mathrm{CDCl}_{3}\right)$ : 19.8. Crystal structure analysis of 12: Single crystals were obtained by recrystallization from hexane. $\mathrm{C}_{36} \mathrm{H}_{44} \mathrm{~N}_{2} \mathrm{O}_{4} \mathrm{Si}_{2}, M_{\mathrm{r}}=624.91, T=90(2) \mathrm{K}$, 
monoclinic, space group $P 2_{1} / c, a=17.8374(6), b=16.3345(6), c=$ 12.0348(4) $\AA, \beta=98.524(2)^{\circ}, V=3467.8(2) \AA^{3}, Z=4, \rho_{\text {calcd }}=1.197 \mathrm{Mgm}^{-3}$, $\mu\left(\right.$ Mo K $\left.\mathrm{K}_{\alpha}\right)=0.142 \mathrm{~mm}^{-1}, F(000)=1336,2 \theta_{\max }=60.0^{\circ}, 63330$ collected reflections, 10104 unique reflections $\left(R_{\text {int }}=0.0369\right)$, 448 parameters, $S=1.063$, $R_{1}=0.0785(I>2 \sigma(I)), w R_{2}$ (all data $)=0.2174$, max. $/ \mathrm{min}$. residual electron density $+0.986 /-0.598 \mathrm{e}^{-3}$.

Synthesis of compound 13: To a solution of $12(9.10 \mathrm{~g}, 14.5 \mathrm{mmol})$ in toluene $(75 \mathrm{~mL})$, which was stirred at ambient temperature, phenyltrifluorosilane $(2.40 \mathrm{~g}, 14.8 \mathrm{mmol})$ was added dropwise followed by heating to $60{ }^{\circ} \mathrm{C}$. Since there was no indication for a reaction between 12 and $\mathrm{PhSiF}_{3}$ (neither evolution of gaseous $\mathrm{Me}_{3} \mathrm{SiF}$ nor precipitation of product), the solution was cooled to room temperature, some crystals (ca. $20 \mathrm{mg}$ ) of tetrabutylammonium fluoride were added and the solution was again heated to $60{ }^{\circ} \mathrm{C}$, whereupon evolution of $\mathrm{Me}_{3} \mathrm{SiF}$ and precipitation of complex 13 commenced. The mixture was then heated to reflux and kept under reflux for $2 \mathrm{~h}$. Then the suspension was cooled to room temperature and the solid white product was filtered off, washed with toluene $(40 \mathrm{~mL})$ and dried in vacuo. Yield: $7.70 \mathrm{~g}(12.7 \mathrm{mmol}, 88 \%)$. C/H/N analysis found (\%): C 71.78, $\mathrm{H} 5.21$, $\mathrm{N}$ 4.89. Calcd. for $\mathrm{C}_{36} \mathrm{H}_{31} \mathrm{~N}_{2} \mathrm{O}_{4} \mathrm{SiF}(602.73)(\%)$ : C 71.74, $\mathrm{H} \mathrm{5.18,} \mathrm{N} \mathrm{4.65.}{ }^{1} \mathrm{H}$ NMR ( $\left.\delta / p p m, \mathrm{CDCl}_{3}\right): 3.1-3.4\left(\mathrm{~m}, 4 \mathrm{H}, \mathrm{N}-\mathrm{CH}_{2}\right), 3.81\left(\mathrm{~s}, 6 \mathrm{H}, \mathrm{O}-\mathrm{CH}_{3}\right), 6.18$ (dd, $2 \mathrm{H}, 2.4 \mathrm{~Hz}, 9.2 \mathrm{~Hz}$ ), 6.64 (d, $2 \mathrm{H}, 9.2 \mathrm{~Hz}), 6.66$ (d, $2 \mathrm{H}, 2.4 \mathrm{~Hz}), 7.0$ $7.6(\mathrm{~mm}, 15 \mathrm{H}) .{ }^{13} \mathrm{C} \mathrm{NMR}\left(\delta / \mathrm{ppm}, \mathrm{CDCl}_{3}\right): 47.7\left(\mathrm{~N}-\mathrm{CH}_{2}\right), 55.4\left(\mathrm{OCH}_{3}\right)$, $104.1,107.3,113.6,125.8,126.3,126.5,126.9,128.9,129.2,129.3,133.0$, $134.3,135.0,159.0,165.3,165.9,171.9 .{ }^{29} \mathrm{Si}$ NMR $\left(\delta / \mathrm{ppm}, \mathrm{CDCl}_{3}\right):-180.3$ $\left(\mathrm{d},{ }^{1} J_{\mathrm{SiF}} 166 \mathrm{~Hz}\right)$.

Synthesis of compound 14: To a solution of $12(6.50 \mathrm{~g}, 10.4 \mathrm{mmol})$ in toluene $(40 \mathrm{~mL})$, which was stirred at ambient temperature, a solution of $\mathrm{SiCl}_{4}(1.77 \mathrm{~g}, 10.4 \mathrm{mmol})$ in toluene $(20 \mathrm{~mL})$ was added dropwise, whereupon a fine yellow precipitate formed within some minutes. Within 4 weeks storage at ambient temperatures this precipitate re-crystallized to yield the solvate 14.toluene as a beige crystalline solid, which was separated from the solution by decantation, washed with toluene $(10 \mathrm{~mL})$ and dried in vacuo. Yield: $6.60 \mathrm{~g}(9.86 \mathrm{mmol}, 95 \%) . \mathrm{C} / \mathrm{H} / \mathrm{N}$ analysis found $(\%)$ : $\mathrm{C} 66.33, \mathrm{H} 5.38$, $\mathrm{N}$ 4.23. Calcd. for $\mathrm{C}_{37} \mathrm{H}_{34} \mathrm{~N}_{2} \mathrm{O}_{4} \mathrm{SiCl}_{2}$ (669.65) (\%): C 66.36, H 5.12, N 4.18

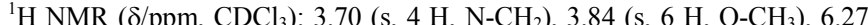
(dd, 2 H, 2.4 Hz, 9.2 Hz), 6.64 (d, 2 H, $9.2 \mathrm{~Hz}), 6.70$ (d, $2 \mathrm{H}, 2.4 \mathrm{~Hz}), 7.25$ $7.30(\mathrm{~m}, 4 \mathrm{H}), 7.45-7.55(\mathrm{~m}, 6 \mathrm{H}) .{ }^{13} \mathrm{C} \mathrm{NMR}\left(\delta / \mathrm{ppm}, \mathrm{CDCl}_{3}\right): 47.8\left(\mathrm{~N}-\mathrm{CH}_{2}\right)$ $55.7\left(\mathrm{OCH}_{3}\right), 104.0,109.3,112.2,126.2,129.2,129.8,134.2,134.6,163.4$, 167.1, 171.8. ${ }^{29} \mathrm{Si} \mathrm{NMR}\left(\delta / \mathrm{ppm}, \mathrm{CDCl}_{3}\right)$ : -183.7 . Crystal structure analysis of 14.toluene: Single crystals were obtained from the reaction mixture. $\mathrm{C}_{37} \mathrm{H}_{34} \mathrm{~N}_{2} \mathrm{O}_{4} \mathrm{SiCl}_{2}, M_{\mathrm{r}}=669.65, T=183(2) \mathrm{K}$, triclinic, space group $P-1, a=$ 9.8583(3), $b=12.9594(4), c=14.0537(5) \AA, \alpha=94.948(2), \beta=105.219(2)$, $\gamma=102.616(2)^{\circ}, V=1670.90(10) \AA^{3}, Z=2, \rho_{\text {calcd }}=1.331 \mathrm{Mgm}^{-3}, \mu\left(\mathrm{Mo} \mathrm{K}_{\alpha}\right)$ $=0.273 \mathrm{~mm}^{-1}, F(000)=700,2 \theta_{\max }=54.0^{\circ}, 27801$ collected reflections, 7292 unique reflections $\left(R_{\text {int }}=0.0316\right), 478$ parameters, $S=1.028, R_{1}=0.0335$ $(I>2 \sigma(I)), \quad w R_{2}$ (all data) $=0.0892, \quad \mathrm{max} . / \mathrm{min}$. residual electron density $+0.274 /-0.276 \mathrm{e}^{-3}$

Synthesis of compound 15: A suspension of 14.toluene (1.05 g, $1.57 \mathrm{mmol})$ and $\mathrm{ZnF}_{2}(0.30 \mathrm{~g}, 2.9 \mathrm{mmol})$ in THF $(40 \mathrm{~mL})$ was stirred at ambient temperature for $12 \mathrm{~d}$. Then the volume was diminished to ca. $15 \mathrm{~mL}$ by removal of volatiles in vacuo and the mixture was stored at $8^{\circ} \mathrm{C}$ for $7 \mathrm{~d}$. The solid thus obtained was filtered off, washed with THF $(2 \mathrm{~mL})$ and extracted with chloroform $(4 \mathrm{~mL})$. Upon storage of the extract at $8{ }^{\circ} \mathrm{C}$ the product 15. $\left(\mathrm{CHCl}_{3}\right)_{2}$ crystallized, which was isolated by decantation and briefly dried in vacuo. Yield: $0.47 \mathrm{~g}(0.60 \mathrm{mmol}, 38 \%)$ of colorless crystals. $\mathrm{C} / \mathrm{H} / \mathrm{N}$ analysis found (\%): $\mathrm{C} 48.76, \mathrm{H} \mathrm{3.75}, \mathrm{N} \mathrm{3.60.} \mathrm{Calcd.} \mathrm{for} \mathrm{C}_{32} \mathrm{H}_{28} \mathrm{~N}_{2} \mathrm{O}_{4} \mathrm{SiF}_{2} \mathrm{Cl}_{6}$ (783.35) (\%): C 49.06, H 3.60, N 3.58. ${ }^{1} \mathrm{H}$ NMR ( $\left./ \mathrm{ppm}, \mathrm{CDCl}_{3}\right): 3.57$ (s, 4 $\left.\mathrm{H}, \mathrm{N}-\mathrm{CH}_{2}\right), 3.85\left(\mathrm{~s}, 6 \mathrm{H}, \mathrm{O}-\mathrm{CH}_{3}\right), 6.20(\mathrm{dd}, 2 \mathrm{H}, 2.4 \mathrm{~Hz}, 8.8 \mathrm{~Hz}), 6.61(\mathrm{~d}, 2 \mathrm{H}$, $8.8 \mathrm{~Hz}), 6.72(\mathrm{~d}, 2 \mathrm{H}, 2.4 \mathrm{~Hz}), 7.2-7.3(\mathrm{~m}, 4 \mathrm{H}), 7.4-7.5(\mathrm{~m}, 6 \mathrm{H}) .{ }^{13} \mathrm{C}$ $\mathrm{NMR}\left(\delta / \mathrm{ppm}, \mathrm{CDCl}_{3}\right): 48.7\left(\mathrm{~N}-\mathrm{CH}_{2}\right), 55.5\left(\mathrm{OCH}_{3}\right), 104.1,107.7,113.0$, $126.8,129.1,129.5,134.2,134.5,164.6,166.0,171.7 .{ }^{29} \mathrm{Si}$ NMR $(\delta / \mathrm{ppm}$, $\left.\mathrm{CDCl}_{3}\right)$ : $-187.0\left(\mathrm{t},{ }^{1} J_{\mathrm{SiF}} 174 \mathrm{~Hz}\right)$. Crystal structure analysis of $\mathbf{1 5} .\left(\mathbf{C H C l}_{3}\right)_{2}$ : $\mathrm{C}_{32} \mathrm{H}_{28} \mathrm{~N}_{2} \mathrm{O}_{4} \mathrm{SiF}_{2} \mathrm{Cl}_{6}, M_{\mathrm{r}}=783.35, T=90(2) \mathrm{K}$, triclinic, space group $P-1, a=$ $10.1109(3), b=12.71 .46(4), c=14.6322(5) \AA, \alpha=112.640(2), \beta=$ $100.292(2), \gamma=91.155(2)^{\circ}, V=1699.96(10) \AA^{3}, Z=2, \rho_{\text {calcd }}=1.530 \mathrm{Mgm}^{-3}$, $\mu\left(\mathrm{Mo} \mathrm{K}_{\alpha}\right)=0.592 \mathrm{~mm}^{-1}, F(000)=800,2 \theta_{\max }=92.0^{\circ}, 134572$ collected reflections, 29432 unique reflections $\left(R_{\text {int }}=0.0372\right), 454$ parameters, $S=1.066$, $R_{1}=0.0361 \quad(I>2 \sigma(I)), w R_{2}$ (all data) $=0.1079, \mathrm{max} . \mathrm{min}$. residual electron density $+0.710 /-0.662 \mathrm{e}^{-3}$. Compound 15 proved stable towards catechol! From a 1:1-stochiometric solution of 15. $\left(\mathbf{C H C l}_{3}\right)_{2}$ and catechol $(0.59 \mathrm{mmol}$ each) in chloroform ( $3 \mathrm{~mL})$ the "solvate" $\mathbf{1 5 . o - \mathbf { C } _ { 6 }} \mathbf{H}_{4}(\mathbf{O H})_{2}$ crystallized. Even upon heating this mixture to reflux for $15 \mathrm{~min}$ the ${ }^{1} \mathrm{H}$ and ${ }^{29} \mathrm{Si}$ NMR reveal the undisturbed co-existence of these two compounds without any sign of decomposition reactions. $\mathrm{C} / \mathrm{H} / \mathrm{N}$ analysis found (\%): $\mathrm{C} 65.60, \mathrm{H} 4.91, \mathrm{~N} 4.30$. Calcd. for $\mathrm{C}_{36} \mathrm{H}_{32} \mathrm{~N}_{2} \mathrm{O}_{6} \mathrm{SiF}_{2}$ (654.73) (\%): C 66.04, H 4.93, N 4.28. Crystal structure analysis of $\mathbf{1 5 . o -}-\mathbf{C}_{6} \mathbf{H}_{4}(\mathbf{O H})_{2}: \mathrm{C}_{36} \mathrm{H}_{32} \mathrm{~N}_{2} \mathrm{O}_{6} \mathrm{SiF}_{2}, M_{\mathrm{r}}=654.73, T=$
90(2) $\mathrm{K}$, triclinic, space group $P-1, a=9.9652(2), b=12.9318(4), c=$ 13.1290(3) $\AA, \alpha=97.778(2), \beta=111.920(2), \gamma=102.560(2)^{\circ}, \quad V=$ $1487.59(7) \AA^{3}, Z=2, \rho_{\text {calcd }}=1.462 \mathrm{Mgm}^{-3}, \mu\left(\mathrm{Mo} \mathrm{K}_{\alpha}\right)=0.145 \mathrm{~mm}^{-1}, F(000)$ $=684,2 \theta_{\max }=50.0^{\circ}, 14687$ collected reflections, 5209 unique reflections $\left(R_{\text {int }}=0.0593\right), 432$ parameters, $S=0.978, R_{1}=0.0478 \quad(I>2 \sigma(I)), w R_{2}$ (all data $=0.1032$, max. $/ \mathrm{min}$. residual electron density $+0.249 /-0.342 \mathrm{e}^{-3}$.

Synthesis of compound 16: Diphenyldichlorogermane (3.50 g, $11.7 \mathrm{mmol})$ was added dropwise to a suspension of $1(5.60 \mathrm{~g}, 11.7 \mathrm{mmol})$ and triethylamine $(3.0 \mathrm{~g}, 30 \mathrm{mmol})$ in THF $(200 \mathrm{~mL})$, which was stirred at ambient temperature. After 20 min the solid precipitate was filtered off and extracted with THF from the filtrate. The resulting solution, after removal of ca. $40 \mathrm{~mL}$ of the solvent under reduced pressure, was stored at $8^{\circ} \mathrm{C}$ overnight, followed by filtration. From the filtrate the solvent was removed in vacuo and the yellow solid residue was recrystallized from chloroform $(15 \mathrm{~mL})$ and hexane $(15 \mathrm{~mL})$. The crystals of $\mathbf{1 6 . C} \mathbf{H C l}_{3}$ thus obtained were filtered off, washed with a mixture of chloroform $(5 \mathrm{~mL})$ and hexane $(5 \mathrm{~mL})$ and briefly dried in vacuo. Yield: $2.20 \mathrm{~g}(2.67 \mathrm{mmol}, 23 \%)$. C/H/ $\mathrm{N}$ analysis found $(\%)$ : C 62.44, $\mathrm{H}$ 4.52, N 3.35. Calcd. for $\mathrm{C}_{43} \mathrm{H}_{37} \mathrm{~N}_{2} \mathrm{O}_{4} \mathrm{GeCl}_{3}(\%)$ : C 62.62, H 4.52, N 3.40. ${ }^{1} \mathrm{H}$ NMR (8/ppm, $\left.\mathrm{CDCl}_{3}\right): 3.26\left(\mathrm{~s}, 4 \mathrm{H}, \mathrm{N}-\mathrm{CH}_{2}\right), 3.71\left(\mathrm{~s}, 6 \mathrm{H}, \mathrm{O}-\mathrm{CH}_{3}\right)$, $5.87(\mathrm{dd}, 2 \mathrm{H}, 2.4 \mathrm{~Hz}, 9.2 \mathrm{~Hz}), 6.40(\mathrm{~m}, 4 \mathrm{H}), 7.0-7.8(\mathrm{~mm}, 20 \mathrm{H}) .{ }^{13} \mathrm{C}$ NMR $\left(\delta / p p m, \mathrm{CDCl}_{3}\right): 49.1\left(\mathrm{~N}^{-C_{2}}\right), 55.1\left(\mathrm{OCH}_{3}\right), 105.3,105.4,114.9$ $126.1,126.2,126.8,128.9,129.0,133.2,135.4,136.3,156.7,165.3,168.8$, 173.1. From the filtrate (upon storage at $8^{\circ} \mathrm{C}$ ) some crystals of 16 had formed which were suitable for X-ray diffraction analysis. Crystal structure analysis of 16: $\mathrm{C}_{42} \mathrm{H}_{36} \mathrm{~N}_{2} \mathrm{O}_{4} \mathrm{Ge}, M_{\mathrm{r}}=705.32, T=93(2) \mathrm{K}$, monoclinic, space group $P 2_{1}$, $a=12.7812(10), b=7.1041(5), c=19.1238(16) \AA, \beta=99.810(4)^{\circ}, V=$ $1711.0(2) \AA^{3}, Z=2, \rho_{\text {calcd }}=1.369 \mathrm{Mgm}^{-3}, \mu\left(\mathrm{Mo} \mathrm{K}_{\alpha}\right)=0.941 \mathrm{~mm}^{-1}, F(000)=$ $732,2 \theta_{\max }=50.8^{\circ}, 24464$ collected reflections, 6227 unique reflections $\left(R_{\text {int }}=0.0517\right), 442$ parameters, $S=1.017, R_{1}=0.0330 \quad(I>2 \sigma(I)), \quad w R_{2}$ (all data) $=0.0605$, max. $/$ min. residual electron density $+0.380 /-0.408 \mathrm{e}^{-3}$.

Synthesis of compound 17: A solution of diphenyldichlorotin (4.50 g, 13.1 mmol) in THF (50 mL) was added dropwise to a suspension of $1(6.15 \mathrm{~g}$, $12.8 \mathrm{mmol})$ and triethylamine $(3.0 \mathrm{~g}, 30 \mathrm{mmol})$ in THF $(100 \mathrm{~mL})$, which was stirred at ambient temperature. After $3 \mathrm{~h}$ the $\left[\mathrm{Et}_{3} \mathrm{NH}\right]^{+} \mathrm{Cl}^{-}$precipitate was filtered off and washed with THF $(15 \mathrm{~mL})$. From the combined filtrate and washings the solvent was removed under reduced pressure. The yellow solid residue was recrystallized from chloroform $(25 \mathrm{~mL})$ to yield 17 as a yellow crystalline powder, which was filtered off, washed with chloroform $(10 \mathrm{~mL})$ and dried in vacuo. Yield: $6.70 \mathrm{~g}(8.92 \mathrm{mmol}, 70 \%) . \mathrm{C} / \mathrm{H} / \mathrm{N}$ analysis found (\%): C 67.05, H 4.97, N 3.74. Calcd. for $\mathrm{C}_{42} \mathrm{H}_{36} \mathrm{~N}_{2} \mathrm{O}_{4} \mathrm{Sn}(\%)$ : C 67.13, H 4.83, N 3.73. ${ }^{1} \mathrm{H} \mathrm{NMR}\left(\delta / \mathrm{ppm}, \mathrm{CDCl}_{3}\right): 3.22\left(\mathrm{~s}, 4 \mathrm{H}, \mathrm{N}-\mathrm{CH}_{2}\right), 3.69\left(\mathrm{~s}, 6 \mathrm{H}, \mathrm{O}-\mathrm{CH}_{3}\right)$, $5.8-7.9(\mathrm{~mm}, 26 \mathrm{H}) .{ }^{13} \mathrm{C} \mathrm{NMR}\left(\delta / \mathrm{ppm}, \mathrm{CDCl}_{3}\right): 51.6\left(\mathrm{~N}-\mathrm{CH}_{2}\right), 55.1\left(\mathrm{OCH}_{3}\right)$, $104.9,105.4,115.4,126.4,127.5,127.7,128.8,128.9,135.0,136.2,137.0$, 151.0, 165.1, 171.5, 176.8. ${ }^{119} \mathrm{Sn} \mathrm{NMR}\left(\delta / \mathrm{ppm}, \mathrm{CDCl}_{3}\right)$ : -555.0 . Crystal structure analysis of 17: $\mathrm{C}_{42} \mathrm{H}_{36} \mathrm{~N}_{2} \mathrm{O}_{4} \mathrm{Sn}, M_{\mathrm{r}}=751.42, T=93(2) \mathrm{K}$, triclinic, space group $P-1, a=11.677(4), b=12.902(6), c=14.066(11) \AA, \alpha=$ 100.820(17), $\beta=105.03(2), \gamma=116.520(13)^{\circ}, V=1714.7(17) \AA^{3}, Z=2$, $\rho_{\text {calcd }}=1.455 \mathrm{Mgm}^{-3}, \mu\left(\mathrm{Mo} \mathrm{K}_{\alpha}\right)=0.791 \mathrm{~mm}^{-1}, F(000)=768,2 \theta_{\max }=54.0^{\circ}$, 15393 collected reflections, 7194 unique reflections $\left(R_{\mathrm{int}}=0.0286\right), 442$ parameters, $S=1.036, R_{1}=0.0296(I>2 \sigma(I)), w R_{2}$ (all data) $=0.0698, \mathrm{max} . / \mathrm{min}$. residual electron density $+0.679 /-0.401 \mathrm{e}^{-3}$.

\section{Quantum chemical calculations}

All computational analyses using density functional theory (DFT) calculations were performed with the GAUSSIAN 03 program suite [24]. The cartesian coordinates of atomic positions obtained by X-ray diffraction analyses of 5, 5a, 16 and 17 were used as initial input data and the desired molecules SI, GE, SN, SN', SIa, GEa, SNa were generated therefrom by replacement of $\mathrm{Si}$ vs. Ge vs. Sn and replacement of ligand-bound $\mathrm{Ph}$ - and OMe-groups by hydrogen atoms. In the same manner, the input coordinates for 2' were generated from crystallographic data of 2. The optimization of the molecular structures and further analyses of the model compounds were performed using B3LYP/6-311G(d,p) for 2' and MP2/SDD for SI, GE, SN, SN', SIa, GEa and SNa.

Acknowledgements: This work was supported by Deutsche Forschungsgemeinschaft (DFG).

\section{References}

[1] K. Hensen, T. Zengerly, T. Müller, P. Pickel, Z. Anorg. Allg. Chem. 1988, 558, 21-27. 
[2] a) J. Wagler, U. Böhme, E. Brendler, G. Roewer, Z. Naturforsch. B 2004, 59, 1348-1352; b) I. Kalikhman, S. Krivonos, L. Lameyer, D. Stalke, D. Kost, Organometallics 2001, 20, 1053-1055.

[3] D. Kost, B. Gostevskii, N. Kocher, D. Stalke, I. Kalikhman, Angew. Chem. 2003, 115, 1053-1056; Angew. Chem., Int. Ed. 2003, 42, 10231026.

[4] B. Gostevskii, I. Kalikhman, C. A. Tessier, M. J. Panzner, W. J. Youngs, D. Kost, Organometallics 2005, 24, 5786-5788.

[5] a) J. Wagler, G. Roewer, Z. Naturforsch. B 2006, 61, 1406-1412; b) M. Yamamura, N. Kano, T. Kawashima, J. Organomet. Chem. 2007, 692, 313-325.

[6] a) J. Wagler, U. Böhme, G. Roewer, Organometallics 2004, 23, 60666069; b) D. Kummer, S. C. Chaudhry, W. Depmeier, G. Mattern, Chem. Ber. 1990, 123, 2241-2245.

[7] I. Kalikhman, B. Gostevskii, E. Kertsnus, M. Botoshansky, C. A. Tessier, W. J. Youngs, S. Deuerlein, D. Stalke, D. Kost, Organometallics 2007 , 26, 2652-2658.

[8] a) E. Kertsnus-Banchik, I. Kalikhman, B. Gostevskii, Z. Deutsch, M. Botoshansky, D. Kost, Organometallics 2008, 27, 5285-5294; b) M. Yamamura, N. Kano, T. Kawashima, Tetrahedron Lett. 2007, 48, 40334036.

[9] I. Kalikhman, B. Gostevskii, E. Kertsnus, S. Deuerlein, D. Stalke, M. Botoshansky, D. Kost, J. Phys. Org. Chem. 2008, 21, 1029-1034.

[10]a) K. Lippe, D. Gerlach, E. Kroke, J. Wagler, Inorg. Chem. Commun. 2008, 11, 492-496; b) S. Metz, C. Burschka, R. Tacke, Eur. J. Inorg. Chem. 2008, 4433-4439; c) S. Metz, C. Burschka, D. Platte, R. Tacke, Angew. Chem. 2007, 119, 7060-7063; Angew. Chem., Int. Ed. 2007, 46, 7006-7009.

[11] a) J. Wagler, A. F. Hill, Organometallics 2008, 27, 6579-6586; b) J. Wagler, A. F. Hill, Organometallics 2007, 26, 3630-3632.

[12] J. Wagler, U. Böhme, E. Brendler, S. Blaurock, G. Roewer, Z. Anorg. Allg. Chem. 2005, 631, 2907-2913.

[13]J. Wagler, T. Doert, G. Roewer, Angew. Chem. 2004, 116, 2495-2498; Angew. Chem., Int. Ed. 2004, 43, 2441-2444.

[14]a) J. Wagler, Organometallics 2007, 26, 155-159; b) J. Wagler, E. Brendler, Z. Naturforsch. B 2007, 62, 225-234.

[15] K. Lippe, D. Gerlach, E. Kroke, J. Wagler, Organometallics 2009, 28 , 621-629.

[16] J. Wagler, G. Roewer, Z. Naturforsch. B. 2005, 60, 709-714.
[17] As pointed out in ref. [15], the $\beta$-H-transfer product $\mathbf{9 b}$ which was encountered in the reaction mixtures upon irradiation of 3, 4,9 and 11, was deliberately synthesized by reaction of ligand 1 with phenyldichlorosilane in order to establish its identity. However, from this hydrosilylation approach a mixture of two diastereomers arises, whereas the $\beta$-H-transfer product $\mathbf{9 b}$ is diastereomerically pure, i.e., the transferred $\mathrm{H}$-atom is trans to the $\mathrm{Si}$-bound $\mathrm{Ph}$-group with respect to the (ONNO) ligand plane.

[18]M. S. Singh, P. K. Singh, Main Group Met. Chem. 2000, 23, 183-188.

[19] a) A. Kämpfe, E. Kroke, J. Wagler, Eur. J. Inorg. Chem. 2009, in press; b) M. Schley, J. Wagler, G. Roewer, Z. Anorg. Allg. Chem. 2005, 631, 2914-2918.

[20]G. W. Fester, J. Wagler, E. Brendler, U. Böhme, G. Roewer, E. Kroke, Chem. Eur. J. 2008, 14, 3164-3176.

[21]J. Wagler, U. Böhme, E. Brendler, B. Thomas, S. Goutal, H. Mayr, B. Kempf, G. Ya. Remennikov, G. Roewer, Inorg. Chim. Acta 2005, 358 , 4270-4286.

[22] a) D. J. Darensbourg, P. Ganguly, D. Billodeaux, Macromolecules 2005, 38, 5406-5410; b) H. Jing, S. K. Edulji, J. M. Gibbs, C. L. Stern, H. Zhou, S. T. Nguyen, Inorg. Chem. 2004, 43, 4315-4327; c) M. Calligaris, G. Nardin, L. Randaccio, J. Chem. Soc., Dalton Trans. 1972, 2003-2006.

[23]O. Seiler, C. Burschka, M. Fischer, M. Penka, R. Tacke, Inorg. Chem. 2005, 44, 2337-2346.

[24]M. J. Frisch, G. W. Trucks, H. B. Schlegel, G. E. Scuseria, M. A. Robb, J. R. Cheeseman, J. A. Montgomery, Jr., T. Vreven, K. N. Kudin, J. C. Burant, J. M. Millam, S. S. Iyengar, J. Tomasi, V. Barone, B. Mennucci, M. Cossi, G. Scalmani, N. Rega, G. A. Petersson, H. Nakatsuji, M. Hada, M. Ehara, K. Toyota, R. Fukuda, J. Hasegawa, M. Ishida, T. Nakajima, Y. Honda, O. Kitao, H. Nakai, M. Klene, X. Li, J. E. Knox, H. P. Hratchian, J. B. Cross, C. Adamo, J. Jaramillo, R. Gomperts, R. E. Stratmann, O. Yazyev, A. J. Austin, R. Cammi, C. Pomelli, J. W. Ochterski, P. Y. Ayala, K. Morokuma, G. A. Voth, P. Salvador, J. J. Dannenberg, V. G. Zakrzewski, S. Dapprich, A. D. Daniels, M. C. Strain, O. Farkas, D. K. Malick, A. D. Rabuck, K. Raghavachari, J. B. Foresman, J. V. Ortiz, Q. Cui, A. G. Baboul, S. Clifford, J. Cioslowski, B. B. Stefanov, G. Liu, A. Liashenko, P. Piskorz, I. Komaromi, R. L. Martin, D. J. Fox, T. Keith, M. A. Al-Laham, C. Y. Peng, A. Nanayakkara, M. Challacombe, P. M. W. Gill, B. Johnson, W. Chen, M. W. Wong, C. Gonzalez, and J. A. Pople, Gaussian 03, revision C.02; Gaussian, Inc.: Wallingford, CT, 2004. 
5

6
7

8

9

10

11

12

13

14

15

16

17

18

19

21

22

23

24

25

26

27

29

30

31

32

33

34

35

36

37

38

39

40

41

42

43

44

45

46

47

48

49

50

51

52

53

54

55

56

57

58

59 